\title{
Failed Spinal Anaesthesia- A Review
}

\author{
Agrawal J*, Rajput A and Mittal R \\ Department of Anaesthesiology, Gajra Raja Medical College Gwalior India
}

*Corresponding author: Dr. Jitendra Agrawal, Department of Anaesthesiology Gajra Raja

Medical College Gwalior 474009 M.P, India, Tel: 9300009942; Email: drjagrawal@gmail.com

\section{Review Article}

Volume 4 Issue 1

Received Date: February 14, 2019

Published Date: March 06, 2019

\section{Abstract}

Background: Spinal Anaesthesia is the most commonly used and reliable technique of neuraxial blockade. Possibility of complete or partial failure has been recognized. Dealing with a spinal anaesthetic which is in some way inadequate can be very difficult. Failed subarachnoid block exposes patients to unfavourable experiences of pain and complications of general anaesthesia if given, so the technique must be performed meticulously in a way which minimizes the risk of failure. The present review of failed spinal anaesthesia has considered mechanism of failure which could be due to faulty technique, drug preparation, drug action and anatomical variations in patient's spine leading to abnormal spread of drug. Alternative options for management of inadequate or failed block like repeating the injection, posture correction and sometimes infiltration of local anaesthestics in case of partial block along with sedation. Full documentation of whole procedure including possible cause of failure and events occurred.

Keywords: Failed spinal; Anaesthestic technique; Complications; Partial failure; Complete failure

\section{Intoduction}

Since its introduction in clinical practice by August Bier in year 1899, spinal anaesthesia has gained enormous popularity and has become one of the most commonly used anaesthetic modality. It does not only dodge complications of general anaesthesia, but it's simple, reliable, and cheap procedure and relatively easy to master. However, sometimes we may come across partial or complete failure of spinal anaesthesia. Thus, a practitioner must be aware of all the plausible causes and mechanisms of failure. August bier in year 1899 had proclaimed about Failure of spinal anaesthesia: "Experienced professional, correct technique, single puncture, adequate CSF backflow, effective anaesthetic agent! So, why did it failed? -Capriciousness!!" (launehaft) [1]. as early as in year 1922, Gaston Labat stated that two conditions are absolutely necessary to produce spinal anaesthesia: puncture of dura mater and subarachnoid injection of anaesthetic agent [2]. Inability to achieve these two primary goals due to any cause leads to failure of spinal anaesthesia.

Plethora of publications are available defining failed spinal anaesthesia; however, in a broad sense failed spinal may be considered as failure to provide satisfactory surgical conditions and patients comfort with or without conversion to general anaesthesia. Majority of experienced practitioners consider the incidence of failure of spinal anaesthesia to be extremely low, probably below $1 \%$. However, it could be as high as $17 \%$ in case of inexperienced clinician and other avoidable factors [3]. For this review, we search Google and PubMed database using phrases like "failed spinal anaesthesia" and "failure of subarachnoid block".

\section{Mechanisms of Failure}

The failure could be ascribed to operator, technical, or equipment related problems. Meticulous attention to the following points may help alleviate the failure rate of spinal anaesthesia. Dural puncture Inability: either failure to puncture the dura (dry tap) or obtain free flow of cerebrospinal fluid (CSF) after alleged dural puncture is one of the conspicuous causes of failure of spinal anaesthesia. The main underlying reasons are inability to identify exact skin puncture site to reach subarachnoid space, blocked needle, poor patient positioning, and faulty needle placement 
technique, obesity, anatomical abnormalities, and an anxious patient etc. The role of the assistant in procuring and maintaining the patient's position is always important and can never be undermined [4]. Intervertebral Space must be palpated in longitudinal and horizontal direction to locate exact skin puncture site. Palpation in both directions gives exact location to be punctured.

The conventional surface landmark-based techniques for spinal anaesthesia are mastered by the majority of anaesthesiologists, with approximately $96 \%$ success rates [5]. However, when these landmarks are difficult to identify accurately due to altered patient anatomy, including obesity, age-related changes, and previous spinal surgery, ultrasound might help achieve correct catheter placement [6].

It is always prudent to check the patency of the needle before introducing and not to advance the needle without the stylet in place. Bent or crooked needles should never be taken in use. The patient should be carefully positioned on a firm flat surface with maximal flexion in order to open the lumbar spine, avoiding lateral curvature of the spine. Although the sitting position is often considered easier, no difference between the lateral and sitting positions has been observed in terms of failure rate. The advent of ultrasonography has mitigated risk of traumatic or failed spinal block [7].

Pseudo success of dural puncture must be recognised which is most likely due to excess local anaesthetic solution infiltrated before the procedure or attempting spinal after a prior epidural analgesia has failed. Rarely, puncture of a congenital arachnoid cyst may also be mistaken as free flow of CSF [8].

Intrathecal administration of the entire volume has to be ensured because leakage of injected volume can occur due to loose connection between the needle and the syringe. The position of needle should be kept steady by putting one hand firm against patient's back, while attaching the syringe with it [9]. Aspiration of CSF just before injecting and just before completion of injection of local anaesthetics is the most trusted way of confirming intrathecal delivery of the drug. Some times with finer pencil point needles, CSF aspiration could be challenging. Inadvertent positioning of side port of needle placed across the dura, may end up losing some part of injectate in the epidural or subdural space. Sometimes, a small dural flap which is formed during the procedure may act as a "flap" valve and CSF can be aspirated freely but during injection, an inward displacement of the flap results in loss of volume between the dura and the arachnoid mater [10].

Injection of the correct drug, dose, and volume are of utmost importance. The drug's spread in subarachnoid space and therefore the level of sensory block is determined by the density/baricity of the solution, volume of drug, temperature of drug (temperature affect the baricity of solution and their spread) and patient's position. The spread of isobaric local anaesthetic is far more unpredictable than that of hyperbaric solutions used routinely and associated with risk of thoracic nerve block and hypotension [11]. Hypobaric solutions have got potential benefit when injected in the sitting position, but risk of hypotension is there. Use of adjuvants may have beneficial effect on the onset, duration, and quality of motor block but may not prevent failure. Anatomical factors affecting the normal spine curvatures, like Kyphosis and/ or scoliosis are responsible for the technical difficulty and interference with spread. Pregnancy may further exacerbate both curvature and cardiopulmonary abnormalities in uncorrected scoliosis [12,13]. Unilateral block may be ensued by supporting ligaments within the theca acting as a longitudinal barrier. Very rarely, inadequate spread or failure may be explained by asymptomatic neurological pathology within the vertebral canal [14].

The efficacy and potency of the drugs can have a deleterious effect of various factors such as prolonged exposure to sunlight, excessive dilution of the drug, chemical incompatibility with other drugs, or altered $\mathrm{pKa}$ due to interaction with the alkaline CSF. Resistance to local anaesthetic agent due to mutation of sodium channel has been reported as an underlying cause of ineffective drug action [15].

Formal testing of the block has to be done before letting surgeon begin with surgery. There is no consensus as to the best practice for checking the block. However, modalities like, sensation of cold (ice cubes or ethyl chloride spray), light touch (cotton swab), and loss of motor power are used commonly. Use of pinprick method which was most widely used method previously is no more recommended. It must always be kept in mind that adequate level of the block does NOT guarantee its quality.

\section{How to Approach Inadequate Regional Block}

Failure of a spinal anaesthesia is often associated with serious consequences such as clinical, psychological, and medico-legal, particularly if the failure becomes evident after starting of the surgery. Salvaging of the block should be put on priority and general anaesthesia should be avoided as far as possible. Following measures can be undertaken once the failure becomes explicit: Revive or salvage the failing block by the means of physical manoeuvres like placing the patient on her left lateral along with head low, hip flexion should be limited to straighten the back and obliterate the spine curvature, and valsalva manoeuvre, or coughing (epidural volume expansion). If an epidural catheter is in place, 
cephalad spread of intrathecal drug may be potentiated with additional doses of local anaesthetics or saline. Once the surgery has started, one may be left in misery with failed block as options are very limited. Systemic sedation and/ or analgesia with intravenous opioids, or anxiolysis may be conducive for the breakthrough pain. Inhalation of entonox or local infiltration of the wound may also be taken into consideration. BR epetition of the regional block for a failed spinal may be reasonable option if feasible. After waiting for 20 minutes in order to avoid pseudo failure, a different inter space must be tried to avoid anatomic distortions. In case of partial failure, some amount of drug must be there in the CSF; hence, it would be prudent to reduce the dose by $25 \%-30 \%[16]$.

Conflicting evidences are present in the literature regarding safety of repeat spinal anaesthetic. There are some concerns with it such as unpredictable spread of drug resulting in a high or total spinal anaesthesia. Sometimes, the repeat block may worsen the hemodynamic without improving the block. The high concentration of drugs on the nerve roots may end up causing cauda equina syndrome [17]. Multiple attempts can potentiate the risk of postdural puncture headache or vascular injury leading to spinal or epidural haematoma, risk of nerve damage due to direct needle trauma is also a theoretical possibility. If the repeat spinal fails to produce desired block, general anaesthesia is the last option to resort upon.

In combined spinal epidural, inadequate spinal block can be approached by injecting saline or incremental doses of local anaesthetic through the epidural catheter in order to increase the block height by squeezing the intrathecal space. If spinal block cannot be elicited even after 15-20 minutes of injection, epidural catheter can be taken in use to establish surgical anaesthesia. Recourse togeneral anaesthesia remains last and perpetual resort in a failed regional block. However, it should be taken into consideration after a prompt and thorough assessment of the situation using common sense and clinical experience, without compromising patient's safety or comfort. Converting to general anaesthesia is not without risks like hypotension on induction, aspiration, and potentially difficult airway etc.

\section{Conclusion}

No matter how low the failure rates are, especially in expert hands, one should always be prepared for failure and shouldn't let surgeon start with surgery till gets fully assured about the block. Patient's safety and demand are always important. Conspicuous and meticulous notes should always be put on desired place to parry medico legal issues. In the end, this review can be summed up elucidating that second spinal in the management of failed block is a safe and reliable method. However, volume of local anaesthetics and position of patient immediately after second spinal must be dealt with utmost circumspection since chances of overdose (cauda equina) and high spinal are fairly high. Surgeon's cooperation is highly desired for repetition of spinal and obviously circumstances should also be taken into consideration.

\section{Future Perspective}

The use of ultrasound has become common to facilitate central venous catheterization, arterial line placement and difficult venous access. Many studies has shown ultrasound to produce faster onset times and longer duration of regional blocks when compared with other nerve localization techniques $[18,19]$. The advent of ultrasound guidance has popularized use of regional anaesthetic techniques as well as increased its use among anaesthesiologists. Having seen these positive effects of ultrasonography, there is now significant momentum to apply this technology to neuraxial blocks.

\section{References}

1. Di Cianni S, Rossi M, Casati A, Cocco G Fanelli G, et al. (2008) Spinal anesthesia: an evergreen technique. Acta Biomed Ateneo Parmense 79(1): 9-17.

2. Labat G (1993) Regional Anesthesia: Its technique and Clinical Applications. Philadelphia: WB Saunders, Philadelphia.

3. Levy JH, Islas JA, Ghia JN, Turnbull CA (1985) retrospective study of the incidence and caues of failed spinal anesthetics in a university hospital. Anesth Analg 64(7): 705-710.

4. Rubin AP (2003) Spinal anaesthesia. In: Wildsmith JAW, et al (Eds.) Principles and Practice of Regional Anaesthesia ( $3^{\text {rd }}$ edn), Edinburgh: Churchill Livingstone.

5. Munhall RJ, Sukhani R, Winnie AP (1988) Incidence and etiology of failed spinal anesthetics in a university hospital: a prospective study. Anesth Analg 67(9): 843848.

6. National Institute for Health and Clinical Excellence (2008) Ultrasound guided catheterization of the epidural space: understanding NICE guidance.

7. Tarkkila PJ (1991) Incidence and causes of failed spinal anesthetics in a university hospital: a prospective study. Reg Anesth 16(1): 48-51.

8. Thomson GE, McMahon D (1993) Spinal needle manufacture, design and use. Bailliere's Clin Anaesthesiol 
7(3): 817-830.

9. Wildsmith JAW, McClure JH, Brown DT, Scott DB (1981) Effects of posture on the spread of isobaric and hyperbaric amethocaine. Br J Anaesth 53(3): 273-278.

10. Berman AT, Cohen DL, Schwentker EP (1982) the effects of pregnancy on idiopathic scoliosis. A preliminary report on eight cases and a review of the literature. Spine 7(1): 76-77.

11. Chopra S, Adhikari K, Agarwal N, Suri V, Sikka P (2011) Kyphoscoliosis complicating pregnancy: Maternal and neonatal outcome. Arch Gynecol Obstet 284(2): 295297.

12. Kavlock R, Ting PH (2004) Local anesthetic resistance in a pregnant patient with lumbosacral plexopathy. BMC Anesthesiol 4(1): 1.

13. Drasner K (2009) Spinal anaesthesia: A century of refinement, and failure is still an option. Br J Anaesth 102(6): 729-730.
14. Drasner K, Rigler ML (1991) Repeat injection after a 'failed spinal': at times, a potentially unsafe practice. Anesthesiology 75(4): 713-714.

15. Lee H, Shin I, Sohn J, Chung Y (2008) Cauda equine syndrome following repeated failed spinal. Reg Anaesth 33(5): P e43E.

16. Ghosh SM, Madjdpour C, Chin KJ (2016) Utrasoundguided lumbar central neuraxial block. BJA Educ 16(7): 213-220.

17. Stace JD, Gaylard DG (1996) Failed spinal anaesthesia. Anaesthesia 51: 892-893.

18. Marhofer P, Kettner SC, Kirchmair L (2010) Fifteen years of ultrasound guidance in regional anaesthesia: part 1. Br J Anaesth 104 (5): 538-546.

19. Abrahams MS, Aziz MF, Fu RF, Horn J (2009) Ultrasound guidance compared with electrical neurostimulation for peripheral nerve block: a systematic review and metaanalysis of randomized controlled trials. $\mathrm{Br} \mathrm{J}$ Anaesth 102(3): 408-417. 